\title{
Salivary Mucocele with Osseous Metaplasia in a Dog
}

\author{
Jin-Kyu PARK ${ }^{1)}$, Jung-Youn HAN ${ }^{1)}$, Il-Hwa HONG ${ }^{1)}$, Ok-Kyung HWANG ${ }^{1)}$, Kyung-Sook HONG ${ }^{1)}$, \\ Ae-Ri JI ${ }^{1}$, Mi-Ran $\mathrm{KI}^{1}{ }^{1}$, Se-Il PARK ${ }^{1)}$, Tae-Hwan $\mathrm{KIM}^{1)}$, Dong-Hag $\mathrm{CHOI}^{2)}$ and Kyu-Shik JEONG ${ }^{1) *}$ \\ ${ }^{1)}$ College of Veterinary Medicine, Kyungpook National University, Daegu 702-701 and \\ ${ }^{2)}$ Dong-In Animal Hospital, Daegu 332, Republic of Korea
}

(Received 8 January 2009/Accepted 16 February 2009)

ABSTRACT. A 4-year-old, male, dachshund was referred to a certain local veterinary hospital because of a soft and fluctuant swelling in the left upper cervical region. The swelling was surgically removed and appeared to be filled with bloody mucus. Grossly, the swelling was identified as salivary mucocele and showed small multifocal whitish ossified tissue on its surface. Microscopically, the wall of salivary mucocele appeared as granulation tissue surrounding mucin, which was composed of loose edematous and vascularized connective tissue containing chronic inflammatory cells such as lymphocytes, plasma cells and macrophages. Characteristically, present case had ossifying components formed by metaplastic spindle cells in the wall of salivary mucocele. Therefore, the present case was diagnosed as salivary mucocele with osseous metaplasia in a dog.

KEY WORDS: canine, osseous metaplasia, salivary mucocele.

A salivary mucocele is an accumulation of saliva that has leaked from a injured salivary gland or duct and is lined with granulation tissue $[4,8]$. Salivary mucoceles can be classified according to the location into cervical mucocele, sublingual mucocele, pharyngeal mucocele, zygomatic mucocele and complex mucocele [4]. A cervical mucocele is an accumulation of saliva in the deeper part of the intermandibular region or the upper cervical region, while a sublingual mucocele (ranula) is formed in the sublingual region, a pharyngeal mucocele in the adjacent tissue to the pharynx, and a zygomatic mucocele in the ventral part of the globe. A complex mucocele is composed of 2 or more types of mucoceles [4]. The most common places in which mucoceles associated with the sublingual gland develop are the cervical, sublingual and pharyngeal areas. The cause of salivary mucocele is not identified, however, blunt trauma, foreign body and sialolith have been suspected as major causes of salivary mucocele [2]. The saliva leaks from the torn salivary gland or duct, and accumulates in the adjacent tissue. Consequently, the accumulated saliva induces an inflammatory response $[1,4,8]$. To prevent saliva from migrating further, the wall of granulation tissue is developed in response to the inflammation. In the present case, an unusual case of salivary mucocele with osseous metaplasia in a dog is described.

A 4-year-old, male, dachshund was referred to a certain local veterinary hospital because of a soft and fluctuant swelling in the left submandibular region. On physical examination, a soft and fluctuant mass was placed subcutaneously in the left upper cervical region. The mass was relatively movable and painless. Through fine needle aspiration, blood-tinged mucus fluid was observed and a

\footnotetext{
* Correspondence to: Professor, Jeong, K.-S., College of Veterinary Medicine, Kyungpook National University, Daegu City 702-701, Republic of Korea (R.O.K).

e-mail: jeongks@knu.ac.kr
}

cervical salivary mucocele was suspected. The fluctuant mass was removed with difficulty surgically under general anesthesia owing to the firm attachment of capsule of the fluctuant mass with adjacent connective tissue (Fig. 1). It was referred to Department of Veterinary Pathology, Kyungpook National University for histopathological examination. Grossly, the excised cystic tissue was well demarcated, hollow and filled with bloody mucus. The diameter of the cystic tissue was approximately $3 \times 2 \mathrm{~cm}$ and it showed small, multifocal, whitish osseous tissue on its surface. The mandibular lymphnode showed normal appearance with no enlargement. The excised cystic tissue was fixed in $10 \%$ formalin and embedded in paraffin wax. The paraffin blocks were sectioned routinely at $4 \mu \mathrm{m}$ thickness and stained with hematoxylin and eosin for histological examinations. Microscopically, there were no salivary acini

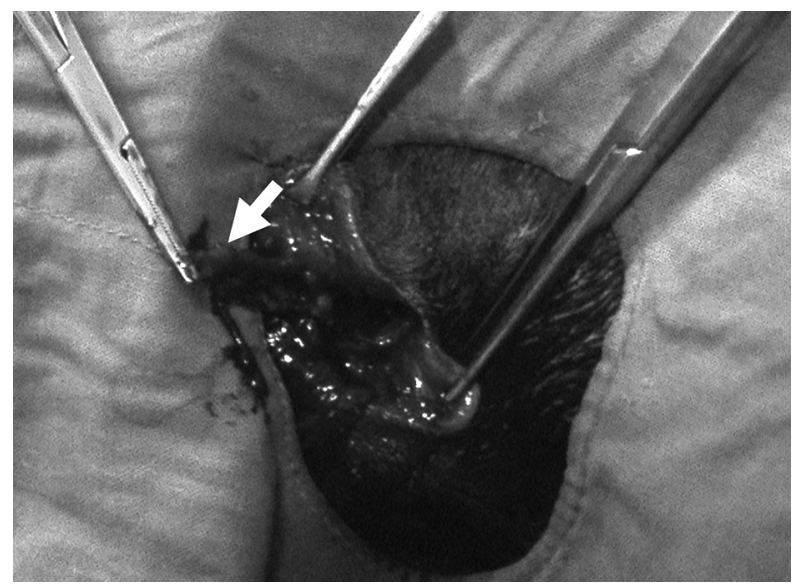

Fig. 1. The fluctuant mass was removed with difficulty surgically owing to the firm attachment of capsule showing whitish osseous tissue (arrow) of the fluctuant mass with adjacent connective tissue. 


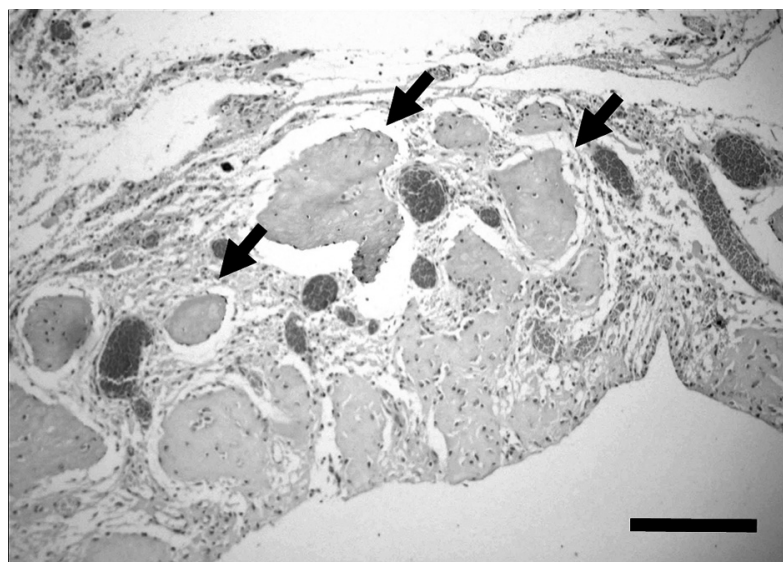

Fig. 2. Spheroid osteoid formation (arrow) was observed in inner surface as well as outer surface of the salivary mucocele wall. The more developed ossification was present in inner surface than outer surface where amorphous spicules of osteoid with neovascularization and proliferation of fibrous connective tissue were mainly present. HE. Bar $=200 \mu \mathrm{m}$.

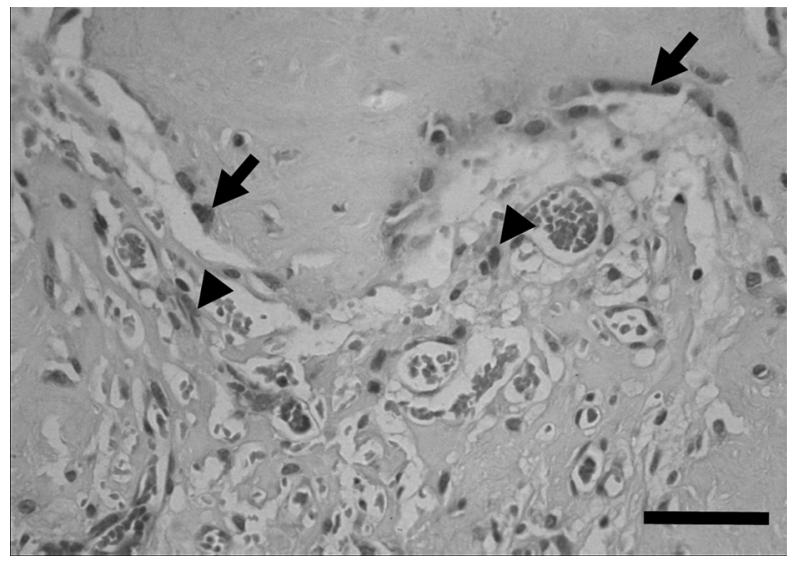

Fig. 3. More developed ossification had osteoblast-like cells and osteocyte-like cells surrounded by bone matrix. The fibrous connective tissue consists of spindle shaped stromal cells which showed metaplastic ossification (arrow head). HE. Bar $=50$ $\mu \mathrm{m}$.

or ducts in the tissues examined. The cystic tissue appeared as granulation tissues without epithelial linings (Fig. 2). The granulation tissue was composed of highly vascularized fibrous stroma. A spheroid osteoid formation was observed in the inner surface as well as the outer surface of the salivary mucocele wall. The more developed ossification was present in the inner surface than the outer surface where amorphous spicules of osteoid with neovascularization and proliferation of fibrous connective tissue were mainly present (Fig. 2). The developed ossification had osteoblastlike cells and osteocyte-like cells surrounded by bone matrix (Fig. 3). The fibrous connective tissue was composed of spindle-shaped stromal cells which showed osseous metaplasia. The highly vascularized connective tissue also contained chronic inflammatory cells such as lymphocytes, plasma cells and macrophages. There was no sign of neoplasia in the adjacent tissue.

In previous cases of salivary mucocele, they were more frequently seen in dogs than cats and there has been a slight predisposition. All dog breeds are susceptible but it seems to be more common in poodles, German shepherds, dachshunds and Australian silky terriers [4]. Clinical signs of salivary mucocele depend on its location. Oral bleeding, respiratory distress, dysphagia and abnormal tongue movements may occur according to the location of salivary mucocele [4]. In case of the cervical mucocle, it is usually asymptomatic and is seen as a gradually growing soft, fluctuant, painless mass in the upper cervical region [4].

Diagnosis of a cervical salivary mucocele usually can be done with no difficulty based on the history, physical examination and cytological examination of the fluid by fine needle aspiration [7]. However, as similar subcutaneous swelling to the cervical salivary mucocele can be associated with sialoadenitis, sialoadenosis, salivary neoplasia, sialolith, cervical abscess, foreign body, hematoma, enlarged lymphnode, tonsil cyst, thyroglossal cyst, cystic Rathke's pouch and brachy cysts, the diagnosis shall be done after differentiating these lesions. The diagnosis of salivary mucocele can be confirmed by using a mucus-specific stain method such as periodic acid-Schiff [2, 3]. Generally, since differentiation of a mucocele from a tumor and congenital cysts is difficult in clinical practice, histopatholgical examination is required for differential diagnosis [2, 4]. Microscopically, the wall of a congenital cyst has a true secretory epithelial lining, whereas salivary mucoceles are lined by granulation tissue $[4,7]$.

Ectopic ossification is the name given to the process of bone formation in abnormal sites [6]. Ectopic ossification can be subdivided into three classifications: heterotopic ossification, osseous metaplasia, and osseus choristoma [6, 7]. The term osseus choristoma means microscopically normal bone in abnormal sites but generally implies a congenital or developmental tumor [7]. Heterotopic ossification usually occurs as secondary to metastatic calcification from systemic disease or dystrophic calcification from local tissue disease $[6,7]$. The other type of ossification is osseus metaplasia and it usually forms another type of connective tissue. Osseous metaplasia shows alternative differentiation of fibroblastic cells into osteogenic cells such as osteoblasts forming osteoid $[5,6]$. The metaplastic bone formed by this osseous metaplasia develops directly from the connective tissue as a consequence of mesenchymal redifferentiation [9]. In the present case, neither metastatic nor dystrophic calcification could be found in the wall of the mucocele but only metaplastic mesencymal cells changing to osteogenic cells were observed. These osteogenic cells showed mature and immature osteoid formation.

Extraskeletal ossification is well known, but it is a rare phenomenon in the salivary mucocele of animals. The pathogenesis of osseous metaplasia in the present case is not known clearly. However, trauma and chronic inflammation have been considered as possible causes of ectopic ossifica- 
tion and calcification in several various cases of dogs $[6,7$, 9]. In the present case, choric inflammation by leaked saliva may be associated to the ectopic ossification. Only one case of salivary mucocle with osseous metaplasia has been reported in veterinary literature [7]. Therefore, the present case will be another rare case of salivary mucocle with osseous metaplasia in veterinary literature.

ACKNOWLEDGEMENT. This work was supported by a grant (code: CBM 31-B3003-01-01-00) from the Center for Biological Modulation of the 21st Century Frontier R\&D Program, the Ministry of Science and Technology, Republic of Korea.

\section{REFERENCES}

1. Ackermann, M. R. 2007. Chronic inflammatioin and wound healing. pp. 183-185. In: Pathologic Basis of Veterinary Disease. 4th ed. (McGavin, M. D. and Zachary J. F. eds.) Mosby, Philadelphia.

2. Brown, N. O. 1989. Salivary gland diseases. Diagnosis, treat- ment, and associated problems. Probl. Vet. Med. 1: 281-294.

3. Dunning, D. 2003. Oral cavity. pp. 553-572. In: Textbook of Small Animal Surgery, 3rd ed. (Slatter, D. ed.) WB Saunders, Philadelphia.

4. Hedlund, C. S. 2002. Surgery of digestive system. pp. 302305. In: Small Animal Surgery, 2nd ed. Mosby. St. Louis.

5. Lynch, G. L. and Scagliotti, R. H. 2007. Osseous metaplasia in the eye of a dog. Vet. Pathol. 44: 222-224.

6. Myers, R. K. and McGavin, M. D. 2007. Cellular and tissue responses to injury. pp. 48-51. In: Pathologic Basis of Veterinary Disease. 4th ed. (McGavin, M. D. and Zachary J. F. eds.) Mosby, Philadelphia.

7. Prassinos, N. N., Tontis, D. K., Adamama-Moraitou, K., Galatos, A. D. and Siochu, A. 2005. Metaplastic ossification of a cervical sialocoele in a dog. Aust. Vet. J. 83: 421-423.

8. Rahal, S. C., Nunes, A. L., Teixeira, C. R. and Cruz, M. L. 2003. Salivary mucocele in a wild cat. Can. Vet. J. 44: 933934.

9. Zotti, A., Fant, P., De, Zan. G., Mollo, A. and Busetto, R. 2007. Chronic cystitis with ossification of the bladder wall in a 6month-old German shepherd dog. Can. Vet. J. 48: 935-938. 